\title{
On Inheritance and Communication of Jiangxi Opera
}

\author{
Yunna Tu \\ Nanchang Institute of Technology, Nanchang Jiangxi, 330000, China
}

Keywords: Jiangxi Opera, Inheritance, Communication.

\begin{abstract}
Jiangxi Opera is a local opera in the Raohe and Xunjiang rivers in the northeast of Jiangxi Province in the Qing Dynasty. Jiangxi Opera has the most significant performance characteristics of the high chamber, Kunlun and Luanqiu performed on the same stage. The formation and development of the Jiangxi Opera is the result of the continuous integration and development of the old and new voices in the Raohe and Xinjiang rivers in the northeast of Jiangxi Province. Jiangxi Opera is a traditional folk opera art. However, in the era of online media, people's lifestyles change faster and faster. The network of information dissemination, fragmentation and economic globalization are developing more and more deeply. The construction of urbanization is becoming more and more rapid, Making Jiangxi Opera is facing the serious challenge of survival and development. The article will carry out a deep cultural perspective on the team Jiangxi Opera opera in order to provide feasible measures for the succession and dissemination of Jiangxi Opera drama.
\end{abstract}

\section{Introduction}

Watching Jiangxi Opera while working hard is the greatest spiritual enjoyment enjoyed by the people of the Raohe and Xunjiang Rivers in the northeast of Jiangxi Province in the old days. They are the most poetic element in ordinary life. In the process of its formation and development, Jiangxi Opera has become an indispensable and important part in the production and life of the people in the eastern part of the country. It has pinned the spiritual world of the villagers and recorded the emotions of the villagers. While performing lively and lively performances on the stage of thousands of years in the rural areas of northeast China, people in northeast China have gained the sense of life and the sense of belonging to their hometown. The northeastern villagers are watching, appreciating, and learning Jiangxi Opera The process is also a cultural identity of Jiangxi Opera and self-confirmation. Jiangxi Opera gradually matures in the course of continuous innovation and integration and development, and precipitates the connotation of Jiangxi Opera.

\section{Definition and classification of Jiangxi Opera}

Jiangxi Opera is not only a symbolic definition of opera art in northeastern Jiangxi, but also a cultural gene of villagers in northeastern Jiangxi. Jiangxi Opera penetration in all aspects of folk production and life in northeastern Jiangxi, is an expression of rural people's concept of value and emotional appeal in northeastern Jiangxi. Jiangxi Opera highly enriched many excellent traditional arts and folk customs in the eastern part of Jiangxi Province, broad and profound, long history of Jiangxi folk culture and folk culture in eastern Jiangxi Province in the fusion of innovation nurtured Jiangxi Opera, whether it is costumes, props and the United States, Repertoire types, performance programs, performance venues, tunes are strong with a strong northeastern Jiangxi ethnic flavor, everywhere in northeastern Jiangxi showed the customs and values recognition. The combination of these factors has become the inner temperament and external form of the Jiangxi Opera, the cultural roots of the Jiangxi Opera, and the cultural identity of the Jiangxi Opera, which is the starting point for the inheritance and dissemination of the Jiangxi Opera.

As far as the material aspect is concerned, the drastic and crude and natural and simple artistic style is the essential expression of the root of the art of Jiangxi Opera opera. This unique artistic style has also made Jiangxi Opera gain a strong mass foundation and dissemination superiority in the 
northeastern Jiangxi and the surrounding areas. Jiangxi Opera further inheritance and development laid the mass foundation. The root cause of the art of Jiangxi Opera is mainly manifested in its open, inclusive and diverse forms of expression. Polygamy is one of the most prominent features of the Jiangxi Opera repertoire. The Jiangxi Opera consists of three kinds of operas: the High Chamber, the Kunqiang Chamber and the Lushu Theater. Each chamber has its own classic repertoire. Rao River's Gypsy opera repertoire mainly Ge Yang, but also with the yellow leather repertoire. Letter River school is mainly a random bullet. Due to the differences of artistic system, musical style and historical inheritance, the three major voices of the Jiangxi Opera also have their own distinctive genres, and the final style of the classic plays is also different. Most of the repertoire genres of Ge Yang cavalry are heroic stories and historical legends. The genre choices of the Kunqu Opera plays mainly in the form of "Wu Xi" and "Ji Qing", while "Zhuang Qiang" relies mainly on the feelings of men and women and family life. Under the background of pluralistic times, the open and inclusive diversity of Jiangxi Opera and its advantage of pluralism provide the basis for self-renewal under the background of economic globalization and cultural diversification. Jiangxi Opera needs to make reasonable adjustments to its own content and constantly innovate and develop. Cultural diversification and economic globalization, we will make great efforts to demonstrate the unique artistic charm of the Jiangxi Opera so that the success of the Jiangxi Opera can be better inherited and disseminated.

\section{The Inheritance and Communication Dilemma of Jiangxi Opera in the Context of Economic Globalization and Cultural Diversification}

The types and types of art are becoming more and more diversified. The rapid development of film and television broadcasting technology has led many of our outstanding traditional plays to be ignored and marginalized. The traditional drama of our country is facing a serious crisis of inheritance and development. As one of the traditional Chinese opera art, the Jiangxi Opera is no exception. Industrialization and economic globalization accelerated the exchange of cultures. The belt also brought a violent impact on the local culture of our country. Various training equipment were not uncommon, and the forms of cultural activities were increasingly diversified. TV shows, variety shows It attracts the people's audio-visual and so on. The contemporary young people prefer to receive new things, the changes of the audience's taste. The impact of the foreign culture makes the traditional drama of our country face the double attack. The accepting groups in Jiangxi Opera are getting smaller and smaller. Nowadays, enjoying and learning drama seems to be something for the elderly. Contemporary youth seldom accept the influence of traditional Chinese culture, they have less understanding and understanding of traditional opera, and are not interested in the study of opera. There is no competition and survivability for the theater without the audience, so we must pay attention to the severe problem of the loss of the theater audience and the shrinking of the market. Drama relies on village groups, but with the accelerating process of urbanization, the village groups gradually disappear, the repertory of the plays disappears, and the drama loses the soil for survival. The inheritance and dissemination of the drama is even harder to achieve. In order to avoid vanishing and continuing to be inherited and disseminated, Jiangxi Opera needs to move from urban areas to urban areas, attracting more young audiences, how to achieve the transition from urban areas to urban areas, and how to attract younger audiences and stimulate their interest in learning. We must think deeply and explore the issue.

Drama is a slow-paced programmatic performance. However, at this stage, the progress of the Internet and science and technology has accelerated the pace of people's lives. The drama lacks the sense of the times and the atmosphere and can not adapt to the fast-paced lifestyle and entertainment of modern people. In addition, there are fewer and fewer creative talents in the development of drama, and the performance of theatrical troupe is more supported by the traditional repertoire, which limits the expansion of the drama market. There are few art theories and research literatures in the Jiangxi Opera, and in order to go international, the Jiangxi Opera needs to innovate on the basis of the traditional elements to realize the combination of the local and the international. In the long history of the river of Jiangxi, Jiangxi Opera can not only inherit. In the current era of globalization, Jiangxi Opera needs to be innovated on the basis of inheritance, and then spread widely and finally to the 
international stage.

\section{Inheritance and Communication Path of Jiangxi Opera under a New Era}

Jiangxi Opera constitutes an important part of our profound cultural heritage and is an important intangible cultural heritage of our country. We have the obligation and responsibility to inherit and disseminate the Jiangxi Opera. The progress of science and technology has enriched the way of life and entertainment. The form of performance art in Jiangxi Opera is single and can not satisfy people's pursuit of sensory stimulation. The modern pursuit of fast-food culture such as games and hip-hop makes Jiangxi Opera gradually disappear in the public's eyes and in memory. When we carry on the inheritance and dissemination of the Jiangxi Opera, we must innovate the Jiangxi Opera on the basis of inheritance.

The government should actively promote the alliance with the media, colleges and universities and enterprises so as to jointly build a culture of Jiangxi Opera and cultivate talents of Jiangxi Opera, The change of the times makes the traditional opera gradually fade from the people's perspective. Many operas face the dilemma of no inheritance. Although the current Jiangxi Opera has not been lost, it also reaches the marginal state. The top priority of the culture of Jiangxi Opera is to solve the problem of inheritance. The inheritance and dissemination of art in Jiangxi Opera is good for carrying forward and disseminating Jiangxi national culture and aesthetic taste so that people can learn more about Jiangxi Poyang culture from a multi-angle perspective, enhance Jiangxi people's recognition of regional culture, better protect the urban cultural and ecological environment and enhance the cohesion of urban culture .

Colleges and universities are places where culture is concentrated, an important place for cultivating talented people, and college students are the trendsetters. College students have a great deal of acceptance of the Jiangxi Opera to define the development prospects of the Jiangxi Opera. Colleges and universities must focus on building and promoting traditional culture, Into teaching, so that more students understand the cultural heritage of the Jiangxi Opera, and then inherit and innovate the Jiangxi Opera, inheritance and development of non-material cultural heritage such as the Jiangxi Dynasty drama and enhance the contemporary college students national pride, which is the inevitable trend of development of higher education. The government should vigorously construct a unique culture of northeastern Jiangxi, strengthen the support for the succession and dissemination of Jiangxi Opera, create a series of Jiangxi Opera, and set up a society of Jiangxi Opera so that more people who love Jiangxi and Jiangxi play a more systematic, comprehensive and in-depth study of Jiangxi Opera and employ professionals for them Teach, teach them the singing of Jiangxi Opera, master the cultural connotation and essence of Jiangxi Opera. Third, the media should continue to step up Jiangxi Opera, let more people know about the existence of the Jiangxi Opera, have an interest in the Jiangxi Opera, stimulate people to appreciate the Jiangxi Opera, appreciate the cultural connotation of the Jiangxi Opera, and we can make a documentary of the Jiangxi Opera Disseminating the origins, prosperousness, decline, features, tracks, status quo, and so forth of the Jiangxi Opera by means of internet technology in a way that is very much appreciated by current young people. Create a unique image of Jiangxi media. The government should conduct joint ventures with enterprises to create a unique cultural product of Jiangxi Opera. The joint action of government, media, colleges and universities and enterprises to jointly build and construct the culture of Jiangxi Opera and cultivate talents of Jiangxi Opera are very beneficial to the inheritance and dissemination of Jiangxi Opera.

\section{Innovate and make general reforms}

Instead of all inheriting the Jiangxi Opera, it inherits critically and retains the classic part of the Jiangxi Opera and the favorite part of the general public, putting forward the useless backward decadent part. To inherit the drama and culture of the Jiangxi Opera is to make the Jiangxi Opera better and better, so it is imperative to carry on the innovation of the Jiangxi Opera. On the basis of inheriting the traditional Jiangxi Opera, we should conform to the development trend of the times, enrich the performance form and drama content of the Jiangxi Opera, make the Jiangxi Opera 
permeate people's life and meet the growing spiritual needs of the general public. New things and foreign culture attract people's audio-visual, art form is more rich and varied, Jiangxi Opera only innovation can attract the public's cause, get a glimpse of life.

We can vigorously develop products around the Jiangxi Opera to attract people's attention and inspire people's curiosity about the Jiangxi Opera. Such as the sale of Jiangxi Opera costumes, posters, figurines figurines, cell phone ornaments, etc. to expand the visibility of Jiangxi Opera, the sale of these products around the Jiangxi Opera economic benefits can be drawn out part of the construction of Jiangxi Opera culture summary, which is very conducive to the development of the cause of Jiangxi Opera. We can combine the essence of the traditional culture of Jiangxi Opera with modern elements to create new content that meets the aesthetic needs of the modern public.

In the performances of the Jiangxi Opera, traditional instruments and accompaniment of western musical instruments can be used together to make the audience have a refreshing experience when they enjoy the Jiangxi Opera. Nowadays there are fewer and fewer people to guide the Jiangxi Opera, and the people who are willing to study the Jiangxi Opera are even more rare. The aging of the actors in the Jiangxi Opera is a serious problem. Therefore, we must inject young blood into the Jiangxi Opera Troupe to improve the welfare of the Jiangxi Opera Troupe and attract more The young people who love Jiangxi Opera join the Jiangxi Opera Troupe.

The development of social informatization and networking has changed people's way of obtaining information. People are more accustomed to browsing through mobile phones, television, telegraph and other devices to obtain the information they need and feel. The inheritance and dissemination of Jiangxi Opera can be based on this feature Such as making an animated cartoon or documentary with the theme of "Jiangxi Opera" to attract the attention of young people and children so that they may understand the culture of Jiangxi Opera and Jiangxi Opera. Due to the emphasis on education of traditional drama and culture, the government education department should increase the proportion of traditional opera culture and education at all levels of school education so that students can understand and approve the traditional drama culture of Jiangxi Opera and our country and expand the awareness of the people in Jiangxi Opera. Jiangxi Opera has a long history of development and is a treasure in the traditional national culture of our country. We can not let the disappearance of the Jiangxi Opera, and make the most effective way to inherit and spread the success of the Jiangxi Opera through the synthesis of the Jiangxi Opera to meet the needs of the new era and meet the needs of the general public.

\section{Raise awareness of protecting Jiangxi Opera}

Jiangxi Opera is an important traditional art and culture in our country. We have a responsibility and obligation to inherit and protect it. In today's society, all kinds of cultures collide with each other. We must strengthen the construction and protection of our own national culture. As one of the traditional arts and culture in our country, the protection of Jiangxi Opera helps to promote the cultural exchange between China and foreign countries and promote the better going out of Jiangxi Opera. The protection of the Jiangxi Opera is the responsibility of each and every one of us. The protection of the intangible cultural heritage also embodies the national strength of a country. If the culture of our nation can not be protected, we can not talk about development. Jiangxi Opera is the wisdom of the majority of workers in Jiangxi Province in our country. We can not let the culture of Jiangxi Opera disappear.

Since the development of Jiangxi Opera, it has experienced the ups and downs of decline. It still stands in the soil of Chinese opera art in ups and downs not only because of its tenacious vitality, but also because of the open, inclusive and diverse features of Jiangxi Opera. Advancing with the times, conform to the development trend of the times. The genre of Jiangxi Opera can accommodate rich and varied people and convey many outstanding qualities to people. It is worth our study, inheritance and development to serve as successors of socialism. We must carry forward the outstanding quality of the Jiangxi Opera and the Jiangxi Opera. Jiangxi Opera is the cognition and longing for the working people in northeastern Jiangxi Province to recognize themselves as well as the worship of a better life. The folk customs, aesthetic taste and values of the northeastern Jiangxi have long been 
deeply integrated into the Jiangxi Opera.

\section{Conclusions}

Jiangxi Opera is a classical drama in northeastern Jiangxi. We not only need to inherit and develop, but also vigorously carry forward and rejuvenate the Jiangxi Opera, demonstrate the culture of Jiangxi distinctively, and promote the charm of the drama culture in our country. With the development of economic globalization, social informatization and networking, cultural confrontations between East and West have been more frequent. Jiangxi Opera has made innovations and developments based on its inheriting traits. With the help of the advantages of modern communication tools, it spread widely and promoted the prosperous prosperity of Chinese culture.

\section{References}

[1] Chen Duo, Ye Changhai. Chinese ancient drama election note, Shanghai Chinese Classics Publishing House, 2010.

[2] Yang Yongmei. The inheritance of the Jiangxi Opera in difficult circumstances, House of drama, 2017.10.

[3] Zou Shengying, Li Fangyuan. New Exploration on the Development and Spread of Jiangxi Opera under the Change of Times, Intelligence, 2013.10.

[4] Zhang Zheng.Study on the Language and Musical Style of Jiangxi Opera, Big stage, 2017.08.

[5] Liu Li. The Formation of Jiangxi Jiangxi Opera Band and the Reform of Aria, Popular literature, 2015.05. 